\title{
Abnormal Pressure Stress Reduces Interleukin-1 $\beta$-Induced Cyclooxygenase-2 Expression in Cultured Rat Vascular Smooth Muscle Cells
}

\author{
Takuji Machida, ${ }^{*}, a$ Tomoko Hinse Endo, ${ }^{a}$ Riho Oyoshi, ${ }^{a}$ Mikiko Yutani, ${ }^{a}$ Maiko Machida, ${ }^{b}$ \\ Saki Shiga, ${ }^{a}$ Hina Murakami, ${ }^{a}$ Sachiko Hiraide, ${ }^{a}$ Masahiko Hirafuji, ${ }^{a, \dagger}$ and Kenji Iizuka ${ }^{a}$ \\ ${ }^{a}$ Department of Pharmacological Sciences, School of Pharmaceutical Sciences, Health Sciences University \\ of Hokkaido; Ishikari-Tobetsu, Hokkaido 061-0293, Japan: and ${ }^{b}$ Division of Pharmacotherapy, Faculty of \\ Pharmaceutical Sciences, Hokkaido University of Science; Sapporo 006-8590, Japan. \\ Received January 26, 2021; accepted April 1, 2021
}

\begin{abstract}
Elevated mechanical stress on blood vessels associated with hypertension has a direct effect on the function of vascular endothelial cells and vascular smooth muscle cells (VSMCs). In the present study, we have identified the effect of pulsatile pressure stress on cyclooxygenase-2 (COX-2) expression induced by interleukin (IL)-1 $\beta$ in cultured rat VSMCs. VSMCs were isolated from aortic media of Wistar rats and cultured. Pulsatile pressure applied to VSMCs was repeatedly given between either 80 and $160 \mathrm{mmHg}$, which simulates systolic hypertension, or 80 and $120 \mathrm{mmHg}$, which simulates normal blood pressure, at a frequency of 4 cycles per min using our original apparatus. Pressure loading that simulates systolic hypertension reduced IL-1 $\beta$-induced COX-2 expression. The pressure also inhibited the rapid and transient phosphorylation of extracellular signal-regulated kinase (ERK) induced by IL-1 $\beta$. IL-1 $\beta$-induced COX-2 expression was significantly inhibited by a specific conventional protein kinase $\mathrm{C}$ (PKC) inhibitor. Pressure loading that simulates systolic hypertension also reduced phorbol myristate 13-acetate (PMA) (a PKC activator)-induced COX-2 expression and the rapid and transient phosphorylation of ERK. Pressure loading that simulates normal blood pressure had no effect on IL-1 $\beta$ - and PMA-induced COX-2 expression. The present study shows that pressure stress between 80 and $160 \mathrm{mmHg}$, which simulates systolic hypertension reduces IL-1 $\beta$-induced COX-2 expression by affecting a mechanism involving PKC and ERK signaling pathways. Downregulation of COX-2 expression in VSMCs by abnormal pressure stress may further worsen local vascular injury associated with hypertension.
\end{abstract}

Key words pulsatile pressure stress; cyclooxygenase-2; interleukin-1 $\beta$; extracellular signal-regulated kinase; protein kinase $\mathrm{C}$; vascular smooth muscle cell

\section{INTRODUCTION}

Vascular endothelial cells and vascular smooth muscle cells (VSMCs) are continuously exposed to not only to biological substances and nerve stimulation but also to mechanical stress associated with blood flow and pulsation. Elevated mechanical stress to vascular walls associated with high pressure modulates vascular remodeling, and certainly plays a role in the pathogenesis of atherosclerosis. ${ }^{1)}$ The mechanical stress applied to vessel walls can be distinguished into three types, i.e., stretch, shear stress, and pressure. Although shear stress due to blood flow is unlikely to be directly affected on VSMCs, pulsatile stretch and pressure due to pulsatile change of blood pressure are directly loaded on VSMCs.

Cyclooxygenase (COX) is a key enzyme catalyzing the rate-limiting step in synthesis of prostaglandin. COX-1 is constitutively expressed in most cells, whereas COX-2 is normally undetectable but is inducible under circumstances such as inflammation with stimulation by variety of cytokines or vasoactive substances. Normal range, i.e., healthy state, of fluid shear stress as well as cyclic stretch are known to induce COX-2 in vascular endothelial cells, ${ }^{2,3)}$ suggesting these

${ }^{\dagger}$ Present address: School of Health Sciences, Iryo Sosei University; Iwaki, Fukushima 970-8551, Japan. mechanical stress-induced COX-2 expressions have a role for a general housekeeping function because prostacyclin $\left(\mathrm{PGI}_{2}\right)$ is predominantly produced by $\mathrm{COX}$ in endothelial cells. $\mathrm{PGI}_{2}$ in vasculature has potent anti-inflammatory, antiplatelet, antiproliferative and vasodilatory effect. ${ }^{4)} \mathrm{PGI}_{2}$ is also produced by COX in VSMCs as the major prostanoid. ${ }^{5)}$ Cytokine, such as interleukin (IL)- $1 \beta$-induced COX-2 expression in VSMCs is thought to function primarily as a defensive and compensatory mechanism for endothelial dysfunction at a local vascular injury site. ${ }^{6)}$ However, effect of pressure stress on COX-2 expression in VSMCs has not been characterized.

We have developed a pulsatile pressure-loading apparatus that can simulate various types of hypertension in cultured cells. ${ }^{7)}$ By using this apparatus, we found that pulsatile pressure that simulates systolic hypertension, suppresses the IL-1 $\beta$-induced expression of inducible nitric oxide synthase (iNOS) ${ }^{8)}$ The mechanism of iNOS suppression by pressure stress involves inhibition of the activation of extracellular signal-regulated kinase (ERK) at the late stage, that is, persistent activation that occurs after $1 \mathrm{~h}$ of IL- $1 \beta$ stimulation. ${ }^{8)} \mathrm{IL}-1 \beta$ is also known to activate ERK at a transient phase peaking at 20-30 min, that is, at the early stage. ${ }^{9,10)}$ But the effect of pulsatile pressure on IL- $1 \beta$-induced ERK activation at the early stage has not been elucidated. The signaling cascade of COX-2 expression in most cells has been well characterized, and the 
protein kinase $\mathrm{C}$ (PKC)- and mitogen-activated protein kinase (MAPK)-mediated signaling cascade is believed to be an important cascade leading to $\mathrm{COX}-2$ induction in VSMCs. ${ }^{11)}$ In fact, phorbol-12-myristate-13 acetate (PMA), a PKC activator, has been shown to induce MAPK as well as COX-2 expression in many cell types including VSMCs. ${ }^{12,13)}$ However, the role of PKC and MAPK for COX-2 expression seems somewhat controversial, with depending on different stimulators and/or different cell types. ${ }^{13-17)}$

In the present study, therefore, we investigated the effect of pulsatile pressure stress between 80 and $160 \mathrm{mmHg}$, which simulates systolic pressure elevation as one of the most common clinical observations of hypertension, on IL- $1 \beta$ - and PMA-induced COX-2 expression as well as transient ERK activation. Based on our results, we propose that pressure stress between 80 and $160 \mathrm{mmHg}$ reduces IL- $1 \beta$-induced COX-2 expression by affecting a mechanism involving PKC and ERK signaling pathways.

\section{MATERIALS AND METHODS}

Cell Culture VSMCs were enzymatically isolated from aortic media obtained from 6-7-week-old Wistar rats using collagenase and elastase. ${ }^{18)}$ Cells were then cultured until confluence, as previously described. ${ }^{18)}$ Primary VSMCs were used throughout the experiments in each figure refers to individual studies on separate primary cultures. At $24 \mathrm{~h}$ before the experiments, the medium was replaced with a serum-free medium containing $0.1 \%$ bovine serum albumin to allow the cells to quiesce. Cells were then treated with IL-1 $\beta$ or PMA. In some experiments, VSMCs were treated with inhibitors of either MAPK or PKC for $1 \mathrm{~h}$ before IL- $\beta$ or PMA stimulation. This study was conducted in accordance with the Guidelines for the Care and Use of Laboratory Animals by the Animal Research Committee of Health Sciences University of Hokkaido, Japan.

Application of Pressure Stress An original design pulsatile pressure-loading apparatus was utilized in the experiments, as described previously. ${ }^{8)}$ In brief, culture dishes were placed in the pressure-loading apparatus, and VSMCs were exposed to pulsatile atmospheric pressure either between 80 and $160 \mathrm{mmHg}$, which simulates systolic hypertension, or between 80 and $120 \mathrm{mmHg}$, which simulates normal blood pressure, at a rate of 4 cycles/min. IL- $1 \beta$ or PMA was added to the culture medium at the beginning of pressurization.

Western Blot Analysis Protein was isolated from VSMCs using buffers and protease inhibitors. Lysate protein was separated out by electrophoresis on either 7.5 or $10 \%$ sodium dodecyl sulfate (SDS)-polyacrylamide gel and transferred to a polyvinylidene difluoride (PVDF) membrane as described previously. ${ }^{15)}$ The blot was incubated for $2 \mathrm{~h}$ with a primary antibody. Subsequently, the immunoblot was incubated with a horseradish peroxidase-conjugated secondary antibody and visualized using an enhanced chemiluminescence kit (Millipore, Billerica, MA, U.S.A.). Anti- $\alpha$-tubulin antibody and anti-total ERK antibody were used as internal controls for COX-2 and phosphorylated ERK, respectively. All bands were analyzed by densitometry using ImageJ software.

Real-Time RT-PCR Total RNA was extracted from cultured VSMCs using the TRI reagent ${ }^{\circledR}$ (Sigma-Aldrich, St. Louis, MO, U.S.A.) according to the manufacturer's instructions. Real-time RT-PCR was carried out using a 7500
Real-Time PCR system (Applied Biosystems, Foster City, CA, U.S.A.) and a SuperScript III Platinum SYBR Green One-Step qRT-PCR Kit (Invitrogen, Carlsbad, CA, U.S.A.), as described previously. ${ }^{15)}$ The primer sequences were also described previously. ${ }^{15)} \beta$-actin mRNA expression was used as the internal control for COX-2 mRNA. The relative expressions of individual targets of mRNA were calculated by $\Delta \Delta^{\mathrm{CT}}$ method.

Materials Fetal calf serum, penicillin, and streptomycin were obtained from Life Technologies (Grand Island, NY, U.S.A.). IL-1 $\beta$ was from BD Biosciences (Bedford, MA, U.S.A.). PMA was from Biomol (Plymouth Meeting, PA, U.S.A.). Anti-COX-2 polyclonal goat antibody was from Santa Cruz Biotechnology (Santa Cruz, CA, U.S.A.). Anti- $\alpha$-tubulin rabbit polyclonal antibody was from Medical \& Biological Laboratories (Aichi, Japan). Bisindolylmaleimide I, Gö 6976, SCH 772984, SB 203580, SP 600125, anti-phosphorylated and total ERK antibodies were from Calbiochem (San Diego, CA, U.S.A.). Horseradish peroxidase-conjugated secondary antibodies were from Invitrogen. The other reagents used in this study were of special grade and purchased from local suppliers unless otherwise noted.

Statistical Analysis Data were presented as mean \pm standard error (S.E.) values of replicate experiments. Statistical analysis was conducted with a two-tailed Student's $t$-test or one-way ANOVA followed by Dunnett's test for multiple comparisons, or two-way ANOVA followed by Tukey's test for multiple comparisons. Significant difference was considered at $p$-values less than 0.05 .

\section{RESULTS}

Pulsatile Pressure between 80-160 mmHg Reduces IL-1/ -Induced COX-2 Expression Pulsatile pressure of $80-160 \mathrm{mmHg}$ suppressed $3 \mathrm{ng} / \mathrm{mL}$ IL- $1 \beta$-induced COX-2 protein expression in a time-dependent manner, in particular at $24 \mathrm{~h}$ (Fig. 1A). When VSMCs were stimulated with 3, 10, or $30 \mathrm{ng} / \mathrm{mL}$ IL- $1 \beta$ for $24 \mathrm{~h}$, COX-2 protein expression was induced in a concentration-dependent manner, and pulsatile pressure suppressed this IL- $1 \beta$-induced COX-2 protein expression (Fig. 1B). Pulsatile pressure significantly suppressed IL-1 $\beta$-induced COX-2 protein and mRNA expression at $24 \mathrm{~h}$ (Figs. 1C, D). Pulsatile pressure itself induced neither COX-2 protein nor mRNA expression (Figs. 1B-D). Pulsatile pressure of $80-120 \mathrm{mmHg}$ had no effect on IL- $1 \beta$-induced COX-2 protein and mRNA expression at 24h (Figs. 2A, B).

Pulsatile Pressure between $80-160 \mathrm{mmHg}$ Reduces IL-1 $\beta$-Induced Transient ERK Phosphorylation IL-1 $\beta$ induced COX-2 protein expression was almost completely inhibited by SCH $772984(1 \mu \mathrm{M})$, an inhibitor of ERK, but not by either SB $203580(1 \mu \mathrm{M})$, an inhibitor of p38 MAPK, or SP $600125(1 \mu \mathrm{M})$, an inhibitor of c-Jun N-terminal kinase (JNK) under non-pressurized condition (Fig. 3A). Therefore, we next examined the effect of pressure stress on IL- $1 \beta$-induced ERK phosphorylation. IL- $1 \beta$ caused the rapid phosphorylation of ERK with a peak at 5-20 min after stimulation with IL-1 $\beta$ (Fig. 3B). At $5 \mathrm{~min}$ after stimulation with IL-1 $\beta$, pulsatile pressure of $80-160 \mathrm{mmHg}$ significantly suppressed ERK phosphorylation (Figs. 3B, C).

Conventional PKC Pathway Is Involved in IL-1 $\beta$-Induced COX-2 Expression Bisindolylmaleimide I acts as a competitive inhibitor of the ATP binding site of PKC, and shows a de- 
A

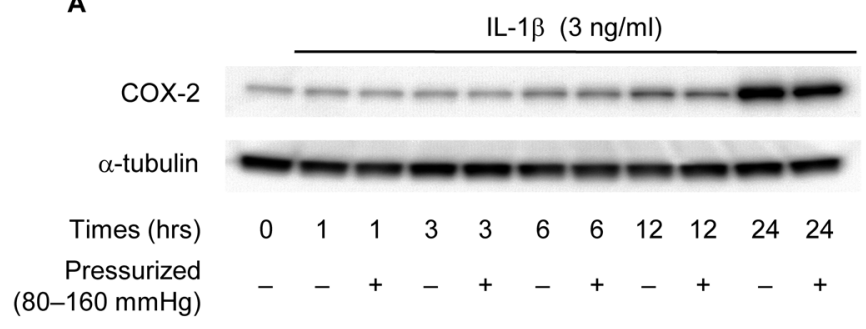

B

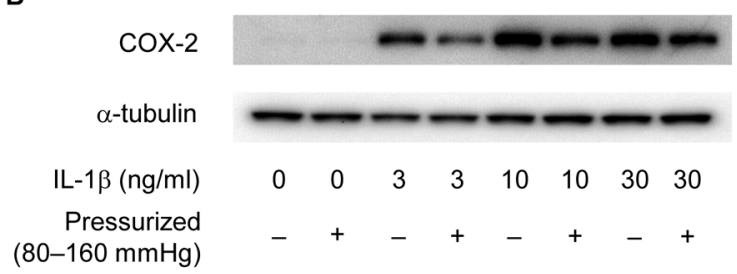

C

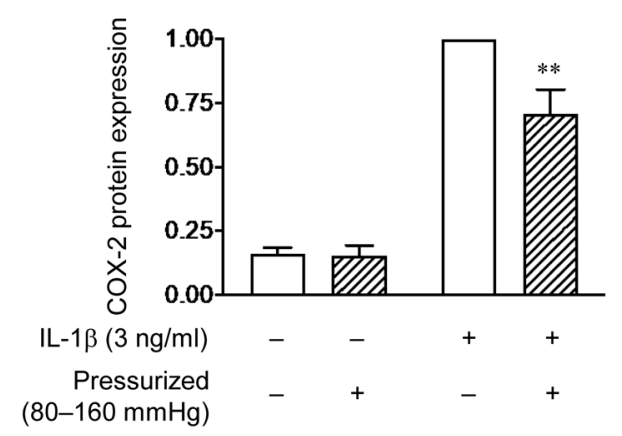

D

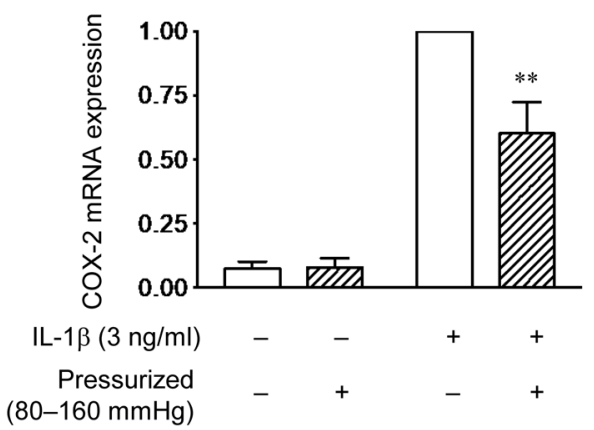

Fig. 1. Effect of the Pulsatile Atmospheric Pressure of $80-160 \mathrm{mmHg}$ on IL- $1 \beta$-Induced COX-2 Expression in Rat VSMCs

The cells were treated with $3 \mathrm{ng} / \mathrm{mL}$ of $\mathrm{IL}-1 \beta$ for the indicated time periods (A) or for $24 \mathrm{~h}(\mathrm{~B}-\mathrm{D})$ in the absence or the presence of pressure stress of $80-160 \mathrm{mmHg}$. COX-2 protein and COX-2 mRNA expression were analyzed by Western blotting and quantitative RT-PCR, respectively. COX-2 protein and mRNA expression was normalized by $\alpha$-tubulin and $\beta$-actin, respectively. $\mathrm{A}$ and $\mathrm{B}$ : The representative protein expression of blotting images of COX-2 and $\alpha$-tubulin. C and D: Summary of analysis expressed by taking samples treated with IL-1 $\beta$ under non-pressurized conditions as 1 . Bars show mean \pm S.E. values $(n=6)$. $* * p<0.01$ $v s$. IL-1 $\beta$ under non-pressurized conditions.

gree of isozyme specificity, with in vitro $\mathrm{IC}_{50}$ values ranging from nanomolar concentration for conventional and novel PKC to $5 \mu \mathrm{M}$ for all $\mathrm{PKC}$ isoforms including the atypical $\mathrm{PKC}{ }^{19)}$ IL- $1 \beta$-induced COX-2 protein expression was almost completely inhibited at 2 and $10 \mu \mathrm{M}$ of bisindolylmaleimide I with or without pulsatile pressure (Figs. 4A, B). Furthermore, Gö $6976(2 \mu \mathrm{M})$, a specific conventional PKC inhibitor, also completely inhibited the COX-2 expression (Fig. 4C).
A

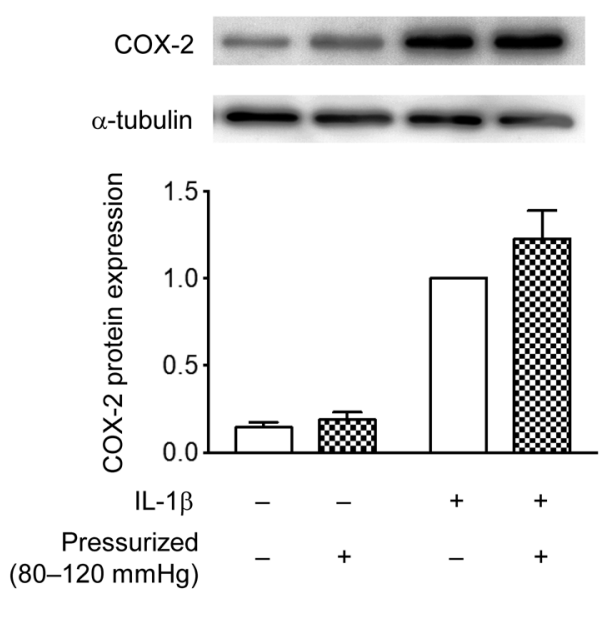

B

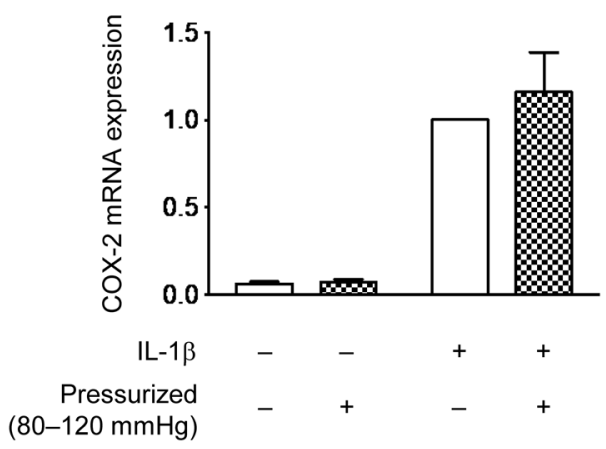

Fig. 2. Effect of the Pulsatile Atmospheric Pressure of $80-120 \mathrm{mmHg}$ on IL-1 $\beta$-Induced COX-2 Expression in Rat VSMCs

The cells were treated with $3 \mathrm{ng} / \mathrm{mL}$ of IL- $1 \beta$ for $24 \mathrm{~h}$ in the absence or the presence of pressure stress of $80-120 \mathrm{mmHg}$. COX-2 protein (A) and COX-2 mRNA (B) expression were analyzed by Western blotting and quantitative RT-PCR, respectively. COX-2 protein and mRNA expression was normalized by $\alpha$-tubulin and $\beta$-actin, respectively. A: Upper panel: representative blotting image of expressions of COX-2 and $\alpha$-tubulin. Lower panel: Summary of densitometric analysis expressed by taking samples treated with IL-1 $\beta$ under non-pressurized conditions as 1 . B: Summary of analysis expressed by taking samples treated with IL-1 $\beta$ under non-pressurized conditions as 1 . Bars show mean \pm S.E. values $(n=6)$.

Pulsatile Pressure between 80-160 mmHg Reduces PMA-Induced COX-2 Expression Pulsatile pressure of $80-160 \mathrm{mmHg}$ suppressed $10 \mathrm{nM}$ PMA-induced COX-2 protein expression in a time-dependent manner, in particular at $1 \mathrm{~h}$ (Fig. 5A). Pulsatile pressure significantly suppressed PMAinduced COX-2 protein expression at $1 \mathrm{~h}$ (Fig. 5B). Because mRNA expression is induced prior to protein expression, we next examined the effect of pulsatile pressure on PMA-induced COX-2 mRNA at $30 \mathrm{~min}$. As a result, pulsatile pressure also significantly suppressed the COX-2 mRNA expression (Fig. 5C). Pulsatile pressure of $80-120 \mathrm{mmHg}$ had no effect on IL-1 $\beta$-induced COX-2 protein expression at $1 \mathrm{~h}$ (Fig. 5D).

Pulsatile Pressure between 80-160 mmHg Reduces PMA-Induced Transient ERK Phosphorylation PMAinduced COX-2 protein expression was almost completely inhibited by SCH $772984(1 \mu \mathrm{M})$, SB $203580(1 \mu \mathrm{M})$ and SP $600125(1 \mu \mathrm{M})$ under non-pressurized condition (Fig. 6A). PMA caused the rapid phosphorylation of ERK with a peak at 5 min after stimulation with PMA (Fig. 6B). At 5 min after stimulation with PMA, pulsatile pressure of $80-160 \mathrm{mmHg}$ significantly suppressed ERK phosphorylation (Figs. 6B, C). 
A

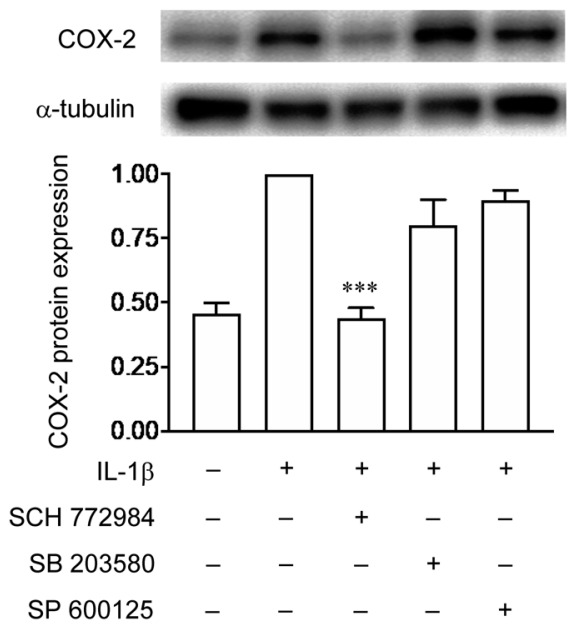

B

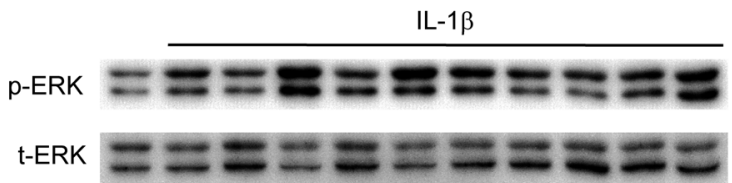

$\begin{array}{llllllllllll}\text { Times }(\min ) & 0 & 5 & 5 & 10 & 10 & 20 & 20 & 30 & 30 & 60 & 60\end{array}$

Pressurized

(80-160 $\mathrm{mmHg})$

C
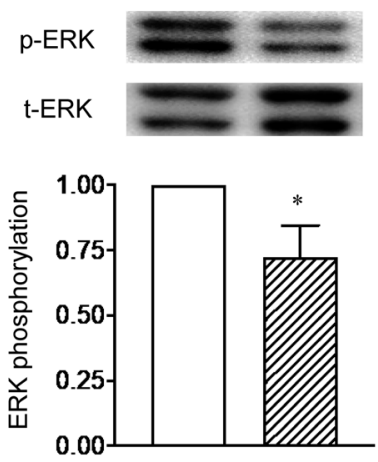

IL-1 $\beta$

Pressurized

$(80-160 \mathrm{mmHg})$

Fig. 3. Suppressive Effect of the Pulsatile Atmospheric Pressure of $80-160 \mathrm{mmHg}$ on IL-1 $\beta$-Induced Transient ERK Activation in Rat VSMCs

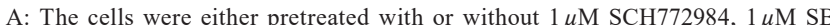
203580 or $1 \mu \mathrm{M} \mathrm{SP} 600125$ for $1 \mathrm{~h}$, and then treated with $3 \mathrm{ng} / \mathrm{mL}$ IL- $1 \beta$ for $24 \mathrm{~h}$. B and $\mathrm{C}$ : The cells were treated with IL- $1 \beta$ for the indicated time periods (B) or $5 \mathrm{~min}$ (C) in the absence or the presence of the pressure stress of $80-160 \mathrm{mmHg}$. COX-2 protein expression and ERK activation were analyzed by Western blotting. COX-2 protein and phosphorylated ERK expression were normalized by $\alpha$-tubulin and total ERK, respectively. A: Upper panel: representative blotting image of expressions of COX-2 and $\alpha$-tubulin. Lower panel: Summary of densitometric analysis expressed by taking samples treated with IL-1 $\beta$ as 1 . B: The representative protein expression of blotting images of COX-2 and $\alpha$-tubulin, and phosphorylated and total ERK, respectively. C: Upper panel: representative blotting image of expressions of phosphorylated and total ERK. Lower panel: Summary of densitometric analysis expressed by taking samples treated with IL-1 $\beta$ under non-pressurized conditions as 1 . Bars show mean \pm S.E. values $\left(n=6\right.$ for A, 7 for C). ${ }^{* * *} p<0.001$, $* p<0.05 v s$. IL- $1 \beta$ under non-pressurized conditions.

\section{DISCUSSION}

This study demonstrated that pulsatile pressure stress be-
A

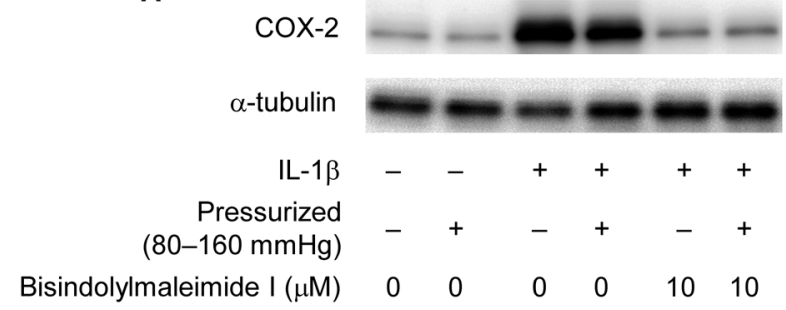

B
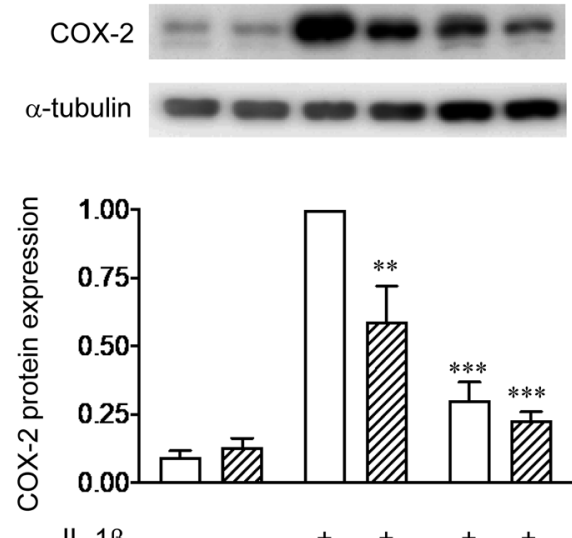

Pressurized

$(80-160 \mathrm{mmHg})$

Bisindolylmaleimide I $(\mu \mathrm{M}) \quad 0 \quad 0 \quad \begin{array}{lllll}0 & 0 & 2 & 2\end{array}$

C
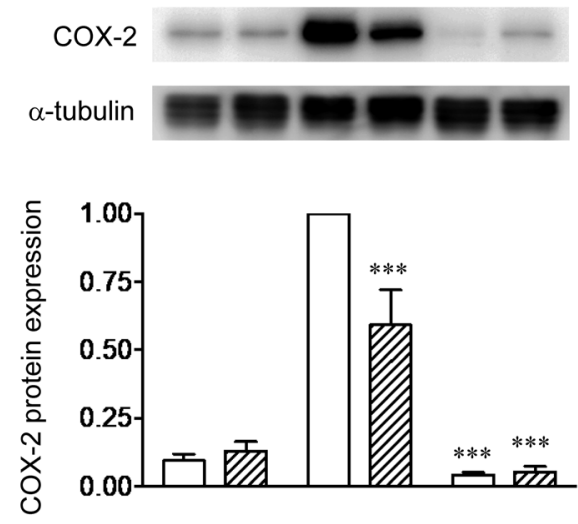

$\mathrm{IL}-1 \beta \quad-\quad-\quad+\quad+\quad+\quad+$

Pressurized _ $+\ldots+\ldots+$

$(80-160 \mathrm{mmHg})+\quad+\quad-\quad+\quad-$

Gö 6976

Fig. 4. Effect of PKC Inhibitors on IL- $1 \beta$-Induced COX-2 Expression in Rat VSMCs

The cells were either pretreated with or without $10 \mu \mathrm{M}$ bisindolylmaleimide I (A), $2 \mu \mathrm{M}$ bisindolylmaleimide I (B) or $2 \mu \mathrm{M}$ Gö $6976(\mathrm{C})$ for $1 \mathrm{~h}$, and then treated with $3 \mathrm{ng} / \mathrm{mL}$ IL- $1 \beta$ for the $24 \mathrm{~h}$ in the absence or the presence of the pressure stress of $80-160 \mathrm{mmHg}$. COX-2 protein expression was analyzed by Western blotting. COX-2 protein expression was normalized by $\alpha$-tubulin. A: The representative protein expression of blotting images of COX-2 and $\alpha$-tubulin. B and C: Upper panel: representative blotting image of expressions of COX-2 and $\alpha$-tubulin. Lower panel: Summary of densitometric analysis expressed by taking samples treated with IL-1 $\beta$ under non-pressurized conditions as 1 . Bars show mean \pm S.E. values $(n=4)$. $* * * p<0.001, * * p<0.01 v s$. IL-1 $\beta$ under non-pressurized conditions.

tween 80 and $160 \mathrm{mmHg}$, which simulates systolic pressure elevation as one of the most common clinical observations of hypertension, suppressed IL- $1 \beta$-induced COX- 2 expression in VSMCs. Our findings also indicate that the suppressive effect 
A

PMA

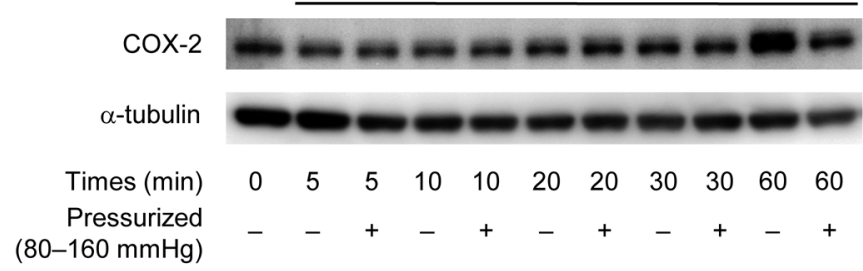

B

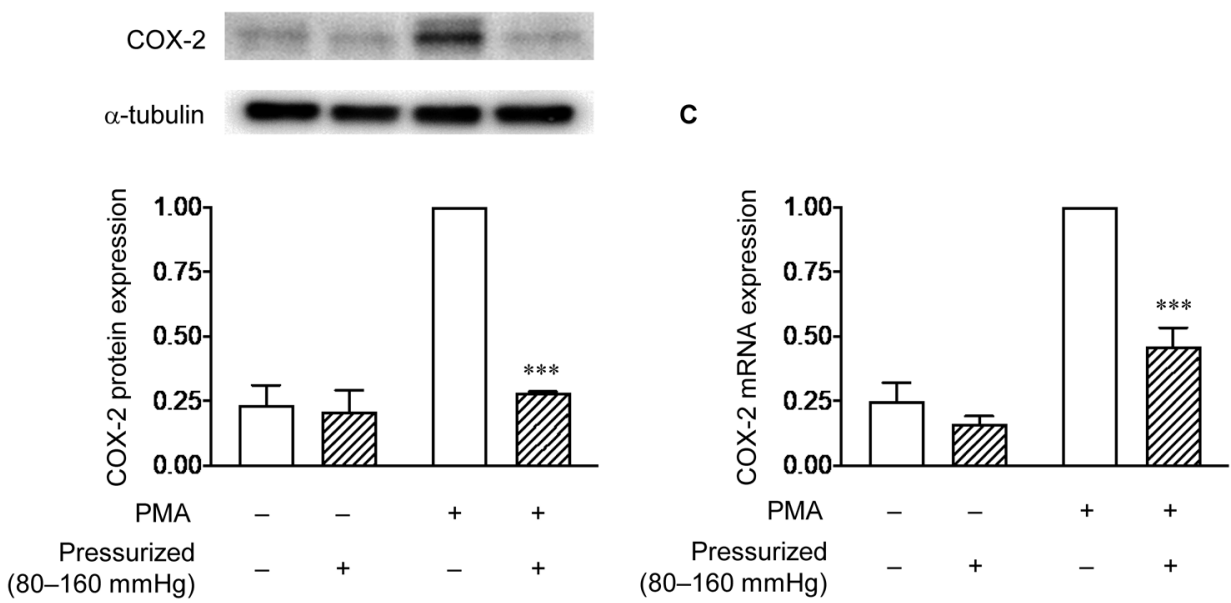

D

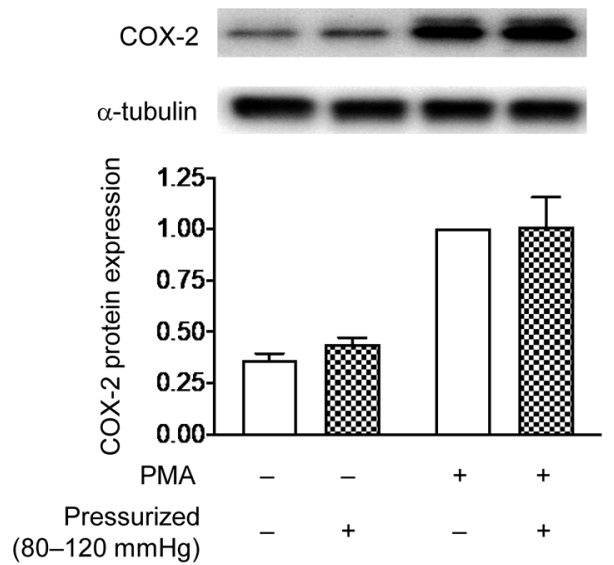

Fig. 5. Effect of the Pulsatile Atmospheric Pressure of $80-160$ or $80-120 \mathrm{mmHg}$ on PMA-Induced COX-2 Expression in Rat VSMCs

The cells were treated with $10 \mathrm{nM}$ PMA for the indicated time periods (A), $1 \mathrm{~h}(\mathrm{~B}, \mathrm{D})$, and $30 \mathrm{~min}(\mathrm{C})$ in the absence or the presence of pressure stress of either $80-160 \mathrm{mmHg}(\mathrm{A}-\mathrm{C})$ or $80-120 \mathrm{mmHg}$ (D). COX-2 protein and COX-2 mRNA expression were analyzed by Western blotting and quantitative RT-PCR, respectively. COX-2 protein and mRNA expression was normalized by $\alpha$-tubulin and $\beta$-actin, respectively. A: The representative protein expression of blotting images of COX-2 and $\alpha$-tubulin. B and D: Upper panel: representative blotting image of expressions of COX-2 and $\alpha$-tubulin. Lower panel: summary of densitometric analysis expressed as a ratio by taking PMA stimulation alone as 1. C: COX-2 mRNA expression. Summary of analysis expressed as a ratio by taking PMA stimulation alone as 1 . Bars show mean \pm S.E. values $(n=3$ for B and D, 4 for C). vs. PMA under non-pressurized conditions. $* * * p<0.001 v s$. PMA under non-pressurized conditions.

of pressure stress on COX-2 expression is dependent on the level of pressure because pressure stress of $80-120 \mathrm{mmHg}$ had no effect on COX-2 expression. In detail, there are two possible reasons for the suppressive effect by high pressure; the one is the increase in the maximal pressure, i.e., $160 \mathrm{vs}$. $120 \mathrm{mmHg}$. The another is the increase in the pressure gradient, i.e., 80 (between 160 and 80) mmHg vs. 40 (between 120 and 80$) \mathrm{mmHg}$. Further studies are required to clarify the detail condition of pressure loading to suppress the COX-2 expression. Also, we found that pressure stress alone had no effect on COX-2 expression. In contrast to our results, application of both shear and stretch within normal range to endothelial cells has been reported to induce COX-2 protein expression without any stimulation. ${ }^{2,3,20)}$

IL- $1 \beta$-induced COX-2 expression was inhibited by an ERK inhibitor, but not by a p38 MAPK inhibitor or a JNK inhibitor, suggesting that ERK activation was essential for the COX-2 expression in our experimental conditions. As mentioned in the Introduction, IL- $1 \beta$ causes biphasic ERK activation, i.e., the early stage and the late stage., ${ }^{9,10)}$ In the present study, we have clarified that pressure stress also inhibited the early stage of ERK phosphorylation, especially at $5 \mathrm{~min}$ after IL-1 $\beta$ stimulation. On the other hand, ERK phosphorylation is reported to be augmented in the vasculature under excessive 
A

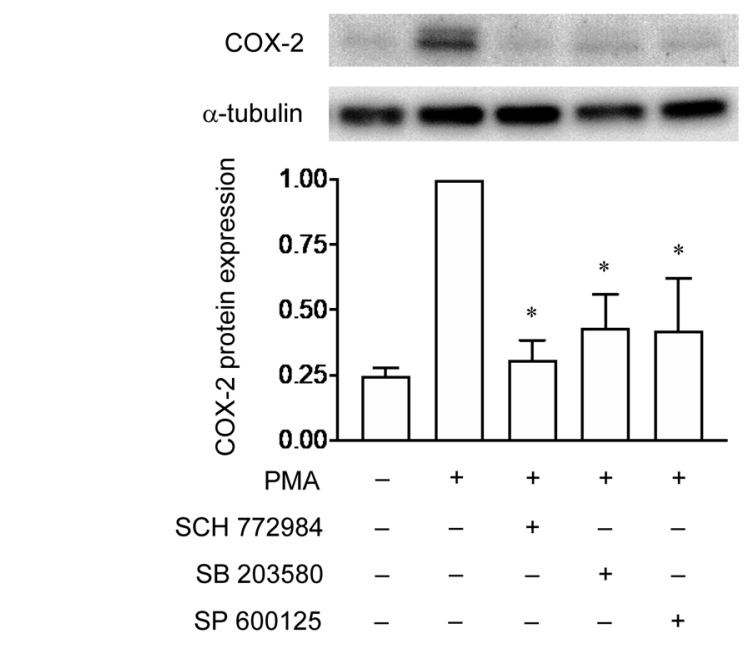

B

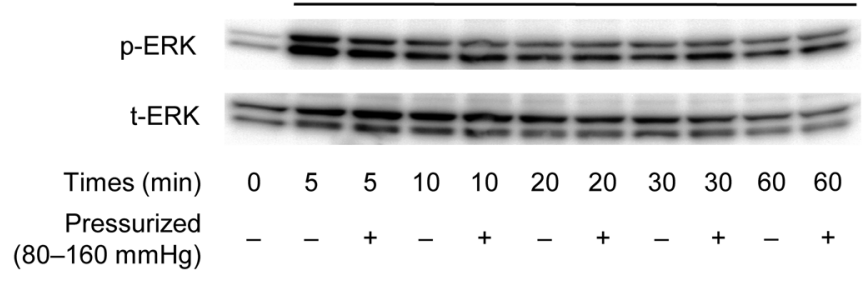

C

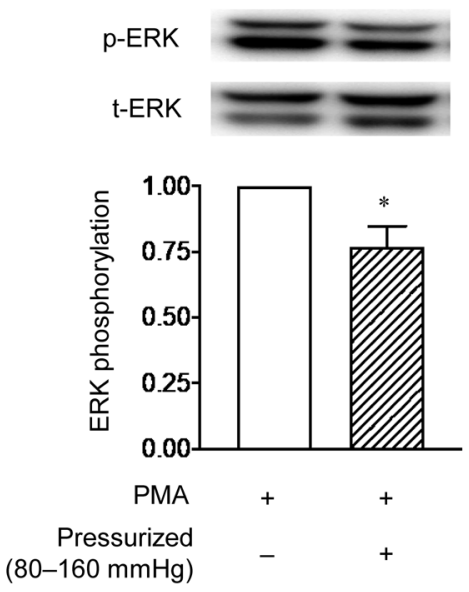

Fig. 6. Suppressive Effect of the Pulsatile Atmospheric Pressure of $80-160 \mathrm{mmHg}$ on PMA-Induced Transient ERK Activation in Rat VSMCs

A: The cells were either pretreated with or without $1 \mu \mathrm{M} \mathrm{SCH772984,} 1 \mu \mathrm{M} \mathrm{SB}$ 203580 or $1 \mu \mathrm{M} \mathrm{SP} 600125$ for $1 \mathrm{~h}$, and then treated with $10 \mathrm{nM}$ PMA for $1 \mathrm{~h}$. B an C: The cells were treated with PMA for the indicated time periods (B) or $5 \mathrm{~min}$ (C) in the absence or the presence of the pressure stress of $80-160 \mathrm{mmHg}$. COX-2 protein expression and ERK activation were analyzed by Western blotting. COX-2 protein and phosphorylated ERK expression was normalized by $\alpha$-tubulin and total ERK, respectively. A: Upper panel: representative blotting image of expressions of COX-2 and $\alpha$-tubulin. Lower panel: Summary of densitometric analysis expressed by taking samples treated with PMA as 1 . B: The representative protein expression of blotting images of COX-2 and $\alpha$-tubulin, and phosphorylated and total ERK, respectively. C: Upper panel: representative blotting image of expressions of phosphorylated and total ERK. Lower panel: Summary of densitometric analysis expressed by taking samples treated with PMA under non-pressurized conditions as 1 . Bars show mean \pm S.E. values $(n=3$ for A, 4 for $\mathrm{C}) .{ }^{*} p<0.05 v s$. PMA under non-pressurized conditions.

pressurized conditions including spontaneously hypertensive rats in the established stage of hypertension, which contributes a vicious circle worsen hypertensive condition through the proliferation of VSMCs. ${ }^{21)}$ Although, we have no clear explanation this contradiction with our present results, it is possible that the upregulation of ERK phosphorylation may be secondary to the elevated blood pressure and consequence of pathological changes in the levels of humoral factors. Further studies are required to clarify the effect of the pressure stress on the proliferation and migration of IL- $1 \beta$-stimulated cells.

The PKC family can be divided into three subgroups, i.e., conventional PKC, novel PKC and atypical PKC, based on their structural characteristics and cofactor requirements. In human gingival fibroblasts and human myometrial smooth muscle cells, atypical PKC has an essential role for IL-1 $\beta$ induced $\mathrm{COX}-2$ expression. ${ }^{22,23)}$ On the other hand, in some cell types COX-2 induction is mediated by conventional PKC. ${ }^{24,25)}$ In the present study, we have tested the role of PKC on IL- $1 \beta$-induced COX- 2 expression in 3 different conditions, i.e., 1) in the presence of $10 \mu \mathrm{M}$ of bisindolylmaleimide $\mathrm{I}$, which inhibits all of three PKC; 2) in the presence of $2 \mu \mathrm{M}$ of bisindolylmaleimide I, which inhibits conventional and novel PKC; 3) in the presence of $2 \mu \mathrm{M}$ Gö 6976, which inhibits conventional PKC. As a result, IL- $1 \beta$-induced COX-2 expression was inhibited by inhibitors of all the conditions tested. These results suggest that conventional PKC plays an important role as a mechanism of the COX-2 expression induced by IL- $1 \beta$. In the present study, we also found that pulsatile pressure between $80-160 \mathrm{mmHg}$, but not $80-120 \mathrm{mmHg}$, suppressed PMA-induced COX-2 expression. Pressure stress suppressed PMA-induced COX-2 mRNA expression at $30 \mathrm{~min}$ after stimulation. These results suggest that the effect of pressure stress on intracellular signal transduction related to COX-2 expression occurs within $30 \mathrm{~min}$ after stress loading. Activation of PKC has been reported to induce COX-2 expression through MAPK including ERK in many cell types including VSMCs. ${ }^{12,26)}$ In fact, all the MAPK inhibitors we tested significantly inhibited PMA-induced COX-2 expression, suggesting both p38 MAPK and JNK signaling pathways are also necessary to induce COX-2. It has also been reported that PMA-induced COX-2 expression was inhibited by an ERK inhibitor, a p38 MAPK inhibitor and a JNK inhibitor in rat cardiac myocytes. ${ }^{12)}$ The $\alpha$-isoform of PKC has been shown to directly phosphorylate Raf-1, providing a link to the ERK. ${ }^{27)}$ Although the precise roles and mechanisms of p38 MAPK and JNK on PMA-induced COX-2 expression were not to be investigated in this study, the inhibition of ERK phosphorylation at the very early stage by pulsatile pressure stress may be involved, at least in part, in the mechanism of the inhibitory effect of COX-2 expression.

COX-2 expression in VSMCs is implicated in several pathological conditions including hypertension. High plasma levels of IL- $1 \beta$ in a patient with essential hypertension have been reported. ${ }^{28)}$ At the site of local vascular injury, IL- $1 \beta$ is actively produced and released from activated macrophages. As prostaglandin $\mathrm{I}_{2}$ has a vasodilating action and inhibitory effects on platelet aggregation and adhesion, leukocyte adhesion, and VSMC proliferation/migration, the induction of COX-2 in VSMCs may function as a defensive mechanism, and its disturbance may contribute to the development of cardiovascular disorders. Thus, pressure stress may affect the outcome of vascular injury via its action on COX-2 induction in VSMCs. In fact, we previously reported that IL- $1 \beta$-induced COX- 2 expression in VSMCs isolated from stroke-prone spontaneously 
hypertensive rats at the very early stage of evolution of hypertension is lower than that in those isolated from age-matched Wistar Kyoto rats. ${ }^{18)}$ Since pressure stress inhibits ERK activation at the early stage, it will be interesting to investigate whether the suppression of COX-2 expression by pressure stress is also observed with other stimulators such as angiotensin $\mathrm{II}^{16)}$ and lysophosphatidylcholine ${ }^{17)}$ in a future study.

In conclusion, pressure stress that simulates systolic hypertension suppresses IL-1 $\beta$ - and PMA-induced COX-2 expression. Inhibition of ERK phosphorylation at the early and late stages by pressure stress may be involved in the mechanism of COX-2 inhibition. Downregulation of COX-2 expression in VSMCs by abnormal pressure stress may further worsen local vascular injury associated with hypertension.

Acknowledgments This study was supported in part by Grants-in-Aid from the Japan Society for the Promotion of Science KAKENHI (Grant Numbers 24790082 and 2686006) and a Grant-in-Aid for the 2007-2008 Research Project of the Research Institute of Personalized Health Sciences, Health Sciences University of Hokkaido.

Conflict of Interest The authors declare no conflict of interest.

\section{REFERENCES}

1) Alexander RW. Theodore cooper memorial lecture. Hypertension and the pathogenesis of atherosclerosis. Oxidative stress and the mediation of arterial inflammatory response: a new perspective. Hypertension, 25, 155-161 (1995).

2) Zhao H, Hiroi T, Hansen BS, Rade JJ. Cyclic stretch induces cyclooxygenase-2 gene expression in vascular endothelial cells via activation of nuclear factor kappa-beta. Biochem. Biophys. Res. Commun., 389, 599-601 (2009).

3) Russell-Puleri S, Dela Paz NG, Adams D, Chattopadhyay M, Cancel L, Ebong E, Orr AW, Frangos JA, Tarbell JM. Fluid shear stress induces upregulation of COX-2 and $\mathrm{PGI}_{2}$ release in endothelial cells via a pathway involving PECAM-1, PI3K, FAK, AND p38. Am. J. Physiol. Heart Circ. Physiol., 312, H485-H500 (2017).

4) Arehart E, Gleim S, Kasza Z, Fetalvero KM, Martin KA, Hwa J. Prostacyclin, atherothrombosis, and cardiovascular disease. Curr. Med. Chem., 14, 2161-2169 (2007).

5) Pritchard KA Jr, O'Banion MK, Miano JM, Vlasic N, Bhatia UG, Young DA, Stemerman MB. Induction of cyclooxygenase-2 in rat vascular smooth muscle cells in vitro and in vivo. J. Biol. Chem., 269, 8504-8509 (1994).

6) Hirafuji M, Machida T, Hamaue N, Minami M. Cardiovascular protective effects of $n-3$ polyunsaturated fatty acids with special emphasis on docosahexaenoic acid. J. Pharmacol. Sci., 92, 308-316 (2003).

7) Iizuka K, Machida T, Kawaguchi H, Hirafuji M. Pulsatile mechanical pressure promotes angiotensin-converting enzyme expression in aortic smooth muscle cells. Cardiovasc. Drugs Ther., 22, 383-390 (2008).

8) Machida $T$, Iizuka $K$, Shinohara S, Hatakeyama N, Nakano K, Kubo Y, Hirafuji M. Pressure stress reduces inducible NO synthase expression by interleukin-1 $\beta$ stimulation in cultured rat vascular smooth muscle cells. Eur. J. Pharmacol., 731, 44-49 (2014).

9) Jiang B, Brecher P, Cohen RA. Persistent activation of nuclear factor- $\alpha \mathrm{B}$ by interleukin- $\beta$ and subsequent inducible NO synthase expression requires extracellular signal-regulated kinase. Arterioscler. Thromb. Vasc. Biol., 21, 1915-1920 (2001).

10) Machida T, Hamaya Y, Izumi S, Hamaya Y, Iizuka K, Igarashi Y,
Minami M, Levi R, Hirafuji M. Sphingosine 1-phosphate inhibits nitric oxide production induced by interleukin- $1 \beta$ in rat vascular smooth muscle cells. J. Pharmacol. Exp. Ther., 325, 200-209 (2008).

11) Chun KS, Surh YJ. Signal transduction pathways regulating cyclooxygenase-2 expression potential molecular targets for chemoprevention. Biochem. Pharmacol., 68, 1089-1100 (2004).

12) Schuette R, LaPointe MC. Phorbol ester stimulates cyclooxygenase-2 expression and prostanoid production in cardiac myocytes. Am. J. Physiol. Heart Circ. Physiol., 279, H719-H725 (2000).

13) Machida $T$, Hiramatsu M, Hamaue N, Minami M, Hirafuji M. Docosahexaenoic acid enhances cyclooxygenase-2 induction by facilitating p44/42, but not p38, mitogen-activated protein kinase activation in rat vascular smooth muscle cells. J. Pharmacol. Sci., 99, 113-116 (2005).

14) Nodai A, Machida T, Izumi S, Hamaya Y, Kohno T, Igarashi Y, Iizuka K, Minami M, Hirafuji M. Sphingosine 1-phosphate induces cyclooxygenase-2 via $\mathrm{Ca}^{2+}$-dependent, but MAPK-independent mechanism in rat vascular smooth muscle cells. Life Sci., 80, 17681776 (2007).

15) Machida T, Ohta M, Onoguchi A, Iizuka K, Sakai M, Minami M, Hirafuji M. 5-Hydroxytryptamine induces cyclooxygenase-2 in rat vascular smooth muscle cells: mechanisms involving Src, PKC and MAPK activation. Eur. J. Pharmacol., 656, 19-26 (2011).

16) $\mathrm{Hu} \mathrm{ZW}$, Kerb R, Shi XY, Wei-Lavery T, Hoffman BB. Angiotensin II increases expression of cyclooxygenase-2: implications for the function of vascular smooth muscle cells. J. Pharmacol. Exp. Ther., 303, 563-573 (2002).

17) Yamakawa T, Ohnaka K, Tanaka S, Utsunomiya H, Kamei J, Kadonosono K. Cyclooxygenase-2 induction by lysophosphatidylcholine in cultured rat vascular smooth muscle cells: involvement of the p38 MAPK pathway. Biomed. Res., 29, 1-8 (2008).

18) Hirafuji M, Tsunoda M, Machida T, Hamaue N, Endo T, Miyamoto A, Minami M. Reduced expressions of inducible nitric oxide synthase and cyclooxygenase-2 in vascular smooth muscle cells of stroke-prone spontaneously hypertensive rats. Life Sci., 70, 917-926 (2002)

19) Martiny-Baron G, Kazanietz MG, Mischak H, Blumberg PM, Kochs G, Hug H, Marme D, Schachtele C. Selective inhibition of protein kinase C isozymes by the indolocarbazole Gö 6976. J. Biol. Chem., 268, 9194-9197 (1993).

20) Di Francesco L, Totani L, Dovizio M, Piccoli A, Di Francesco A, Salvatore T, Pandolfi A, Evangelista V, Dercho RA, Seta F, Patrignani P. Induction of prostacyclin by steady laminar shear stress suppresses tumor necrosis factor-alpha biosynthesis via heme oxygenase-1 in human endothelial cells. Circ. Res., 104, 506-513 (2009).

21) Zhang L, Zhang Y, Wu Y, Yu J, Zhang Y, Zeng F, Shi L. Role of the balance of Akt and MAPK pathways in the exercise-regulated phenotype switching in spontaneously hypertensive rats. Int. J. Mol. Sci., 20, 5690 (2019).

22) Nakao $\mathrm{S}$, Inoue $\mathrm{D}$. Involvement of protein kinase $\mathrm{C}$ in IL- $1 \beta$ induced expression of cyclooxygenase-2 in human gingival fibroblasts. J. Oral Sci., 51, 417-423 (2009).

23) Duggan SV, Lindstrom $T$, Iglesias $T$, Bennett PR, Mann GE, Bartlett SR. Role of atypical protein kinase $\mathrm{C}$ isozymes and NF- $\kappa \mathrm{B}$ in IL- $1 \beta$-induced expression of cyclooxygenase- 2 in human myometrial smooth muscle cells. J. Cell. Physiol., 210, 637-643 (2007).

24) Giroux M, Descoteaux A. Cyclooxygenase-2 expression in macrophages: modulation by protein kinase C- $\alpha$. J. Immunol., 165, 3985-3991 (2000).

25) Molina-Holgado E, Ortiz S, Molina-Holgado F, Guaza C. Induction of COX-2 and $\mathrm{PGE}_{2}$ biosynthesis by IL- $1 \beta$ is medicated by PKC and mitogen-activated protein kinases in murine astrocytes. Br. J. Pharmacol., 131, 152-159 (2000).

26) Baillie G, Mackenzie SJ, Houslay MD. Phorbol 12-myristate 13-acetate triggers the protein kinase A-mediated phosphorylation 
and activation of the PDE4D5 cAMP phosphodiesterase in human aortic smooth muscle cells through a route involving extracellular signal regulated kinase (ERK). Mol. Pharmacol., 60, 1100-1111 (2001).

27) Kolch W, Heidecker G, Kochs G, Hummel R, Vahidi H, Mischak H, Finkenzeller G, Marme D, Rapp UR. Protein kinase C alpha acti- vates Raf-1 by direct phosphorylation. Nature, 364, 249-252 (1993).

28) Dalekos GN, Elisaf M, Bairaktari E, Tsolas O, Siamopoulos KC. Increased serum levels of interleukin- $1 \beta$ in the systemic circulation of patient with essential hypertension: additional risk factor for atherogenesis in hypertensive patient? J. Lab. Clin. Med., 129, 300-308 (1997). 